\title{
Ação do extrato de Arrabidaea chica em biofilmes de Candida albicans, efeito citotóxico em fibroblastos e queratinócitos, e nas propriedades físico/mecânicas de resina de poli(metilmetacrilato)
}

Action of Arrabidaea chica extract on Candida albicans biofilms, cytotoxic effect on fibroblasts and keratinocytes, and on physical/mechanical porperties of poli(methylmethacrylate) resin Acción del extracto de Arrabidaea chica sobre las biopelículas de Candida albicans, efecto citotóxico sobre los fibroblastos y queratinócitos, y sobre las propriedades físico-mecánicas de la resina de poli(metilmetacrilato)

Recebido: 15/09/2021 | Revisado: 28/09/2021 | Aceito: 11/10/2021 | Publicado: 12/10/2021

Camila Maria Martins Brandão

ORCID: https://orcid.org/0000-0003-1194-7964 Universidade Ceuma, Brasil

E-mail: camilammbrandao@hotmail.com

Viviane Hass

ORCID: https://orcid.org/0000-0002-4581-1291 University of Missouri, Estados Unidos

E-mail: vivikl_hass@hotmail.com

Patricia Wiziack Zago

ORCID: https://orcid.org/0000-0001-8336-3357 São Leopoldo Mandic, Brasil

E-mail: patizago@hotmail.com

Lívia Câmara de Carvalho Galvão ORCID: https://orcid.org/0000-0001-9540-649X Universidade Ceuma, Brasil E-mail: livia.camara@ceuma.br

Daniela Bassi Dibai

ORCID: https://orcid.org/0000-0002-6140-0177 Universidade Ceuma, Brasil E-mail: daniela.bassi@ceuma.br

Fabricio Brito Silva

ORCID: https://orcid.org/0000-0002-9878-0206 Universidade Ceuma, Brasil

E-mail: fabricio.brito@ceuma.br

Adriana Santos Malheiros ORCID: https://orcid.org/0000-0003-0500-7829 Universidade Ceuma, Brasil E-mail: asmj71@uol.com.br

Paulo Cézar Simamoto Júnior ORCID: https://orcid.org/0000-0001-6087-9721 Universidade Federal de Uberlândia, Brasil E-mail: psimamoto@gmail.com

Rudys Rodolfo De Jesus Tavarez ORCID: https://orcid.org/0000-0002-3525-9245 Universidade Ceuma, Brasil E-mail: rudysd@uol.com.br

\begin{abstract}
Resumo
Este estudo investigou a ação do extrato hidroalcoóde Arrabidaea chica (AchE) contra C. albicans, bem como seu efeito na citotoxicidade em fibroblastos e queratinócitos e alterações nas propriedades físico/mecânicas de resina de PMMA. A susceptibilidade da $C$. albicans ao AchE foi avaliada por meio da CIM e CFM. Para os testes de suscetibilidade, biofilmes de $C$. albicans foram desenvolvidos em disco de resina acrílica de PMMA por 48 horas e imersos em 5 grupos, tampão fosfato-salino, hipoclorito de sódio 1\% ou em AchE na CIM, 5xCIM ou 10xCIM. A citotoxicidade do AchE $(10,50$ e $100 \mu \mathrm{g} / \mathrm{m})$ em fibroblastos e queratinócitos foi avaliada pelo método MTT sendo a água destilada e $\mathrm{NaOCl} 1 \%$ utilizados como controles. Para avaliação das propriedades físico/mecânicas (rugosidade superficial, alteração de cor e resistência flexural), discos foram imersos nos 5 grupos já descritos. Os discos foram
\end{abstract}


incubados e os testes foram realizados após $0,7,14,21$ e 28 dias de imersão. O AcHE foi considerado um forte inibidor e com potencial bactericida. A $10 \mu \mathrm{g} / \mathrm{mL}$ não apresentou citotoxicidade, comparando-se ao grupo controle. Demais grupos experimentais foram citotóxicos, porém, com valores menores quando comparados ao $\mathrm{NaOCl} 1 \%$. Não houve diferenças significativas nas propriedades físico/mecânicas independente do grupo ou tempo avaliados. O AchE, quando utilizado em altas concentrações, foi citotóxico em células fibroblastos e queratinócitos e, independente das concentrações utilizadas, não interferiu nas propriedades físico/mecânicas das resinas PMMA.

Palavras-chave: Arrabidaea chica; Biofilmes; Candida albicans; Citotoxicidade; Fibroblastos; Queratinócitos; Polimetilmetacrilato.

\begin{abstract}
This study investigated the action of the hydroalcohol extract Arrabidaea chica (AchE) against C. albicans, as well as its effect on cytotoxicity in fibroblasts and keratinocytes and changes in the physical/mechanical properties of PPMA resin. The susceptibility of $C$. albicans to AchE was assessed using the MIC and MFC. For the susceptibility test, $C$. albicans biofilms were developed in PMMA acrylic resin disc for 48 hours and immersed in 5 groups, phosphatesaline buffer, $\mathrm{NaoCl} 1 \%$ or in AchE at CIM, 5xCIM or 10xCIM. The cytotoxicity of AchE (10,50 and $100 \mu \mathrm{g} / \mathrm{mL})$ in fibroblasts and keratinocytes was evaluated by MTT, with distilled water and $\mathrm{NaOCl} 1 \%$ used as controls. For evaluation of physical/mechanical properties, discs were immersed in the 5 already described groups. The discs were incubated and the testes were performed after 0, 7, 14, 21 and 28 days of immersion. Surface roughness, color change and flexural strength were verified. AchE was considered a strong inhibitor and with bactericidal potential. At 10 $\mu \mathrm{g} / \mathrm{mL}$ it did not show cytotoxicity compared to the control group. Other experimental groups were cytotoxic, however, with lower values when compared to $\mathrm{NaOCl} 1 \%$. There were no significant differences in groupindependent physical/mechanical properties or time taken. AchE, when used in high concentrations, was cytotoxic and, regardless of the tools used, it did not interfere with the physical/mechanical properties of PMMA resins.
\end{abstract}

Keywords: Arrabidaea chica; Biofilms; Candida albicans; Cytotoxicity; Fibroblasts; Keratinocytes; Polymethylmethacrylate.

\title{
Resumen
}

Este estudio investigó la acción del extracto de hidroalcohol Arrabidaea chica (AchE) contra C. albicans, así como su efecto sobre la citotoxicidad en fibroblastos y queratinocitos y cambios en las propiedades físico-mecánicas de la resina de PMMA. La susceptibilidad de C. albicans a AchE se evaluó utilizando la CIM y CFM. Para la prueba de susceptibilidad, se desarrollaron biopelículas de C. albicans en disco de resina acrílica de PMMA durante 48 horas y se sumergieron en 5 grupos, tampón fosfato-salino, $\mathrm{NaOCl} 1 \%$ o en AchE en CIM, 5xCIM o 10xCIM. La citotoxicidad de AchE (10,50 y $100 \mu \mathrm{g} / \mathrm{mL})$ en fibroblastos y queratinocitos se evaluó mediante MTT, con agua destilada y $\mathrm{NaOCl} 1 \%$ como controles. Para la evaluación de las propiedades físicas/mecánicas (rugosidad de la superficie, coloración y resistencia a la flexión), los discos se sumergieron en los 5 grupos ya descritos. Los discos se incubaron y los testes se realizaron a los 0,7, 14, 21 y 28 días de inmersión. AcHE se consideró un inhibidor fuerte y con potencial bactericida. A $10 \mu \mathrm{g} / \mathrm{mL}$ no mostró citotoxicidad, en comparación con el grupo de control. Otros grupos experimentales fueron citotóxicos, sin embargo, con valores bajos en comparación con $\mathrm{NaOCl} 1 \%$. No hubo diferencias significativas en las propiedades físicas/mecánicas independientes del grupo o en el tiempo empleado. AchE, cuando se usó en alta concentración, fue citotóxico en células de fibroblastos y queratinocitos y, independientemente de las concentraciones utilizadas, no interfirió con las propiedades físicas/mecánicas de las resinas de PMMA.

Palabras clave: Arrabidaea chica; Biopelículas; Candida albicans; Citotoxicidad; Fibroblastos; Queratinocitos; Polimetilmetacrilato.

\section{Introdução}

A resina acrílica à base de polimetilmetacrilato (PMMA) é comumente utilizada como base de próteses totais e parciais removíveis, graças ao seu fácil processo de fabricação e preço relativamente baixo (El Bahra, et al., 2013). Contudo, o PMMA, quando incorporado às próteses, encontra-se integralmente em contato com a mucosa oral e associado ao fato de que as propriedades inerentes a esse material geram porosidade e rugosidade, há uma maior chance de acúmulo (Zomorodian et al., 2011) e proliferação de microrganismos (Moura et al., 2006). Ademais, a deficiência na higienização das próteses, principal medida utilizada para o controle da colonização fúngica nas superfícies desses aparelhos, resulta em acúmulo de restos alimentares o que facilita a adesão de biofilme. A instalação de um biofilme intensifica a atividade inflamatória e infecciosa na mucosa oral, o que pode levar ao aparecimento de candidose associada à prótese (CAP) (Zomorodian, et al 2011, Lee, et al 2016). 
Diante de uma infecção e para tentar controlar a proliferação do biofilme, vários métodos podem ser utilizados, dentre eles destaca-se a utilização de dentifrício fluoretado associado à escovação dental devido à facilidade de utilização da técnica e o seu baixo custo (Tan et al., 2014). Entretanto, por mais eficaz que seja esse procedimento para a remoção do biofilme dental, essa eficiência por vezes não é observada na desinfecção das próteses contaminadas, visto que porosidades e irregularidades são encontradas em suas superfícies, o que torna a remoção efetiva do biofilme pela escovação, questionável (Glass et al., 2010).

Além disso, pacientes com problemas de coordenação motora possuem dificuldade em realizar de forma adequada tal procedimento (Padilha et al., 2007), bem como pacientes idosos com menos força muscular. Em virtude dessas limitações, o uso de soluções com potencial desinfetante, como o hipoclorito de sódio ( $\mathrm{NaOCl}$ ), é indicado (Orsi et al., 2011, Web et al., 2005). Embora eficiente como agente antimicrobiano, o $\mathrm{NaOCl}$ apresenta desvantagens quanto à sua utilização uma vez que tem alta toxicidade (Solana et al., 2020), capacidade de corroer os metais presentes nas próteses (Felipucci, et al, 2011, Paranhos et al., 2014), possibilidade de clarear a resina acrílica (Felipucci et al., 2011, Paranhos, et al 2014, Paranhos et al., 2009) e aumentar sua rugosidade superficial (Vieira et al., 2010).

Assim, em situações em que a CAP é persistente, são utilizadas medicações como nistatina (Little \& Falace1987) e fluconazol (Correa et al., 2018), que apesar de eficazes, podem ser potencialmente citotóxicos (Correa et al., 2018), e desencadear reações alérgicas, insuficiência renal, necrose hepática e resistência a drogas (Little \& Falace, 1987). Tais estratégias podem, ainda, falhar na remoção do biofilme, (Lucena-Ferreira et al., 2014) seja pela incapacidade inerente dos fármacos, ou pela seleção de cepas resistentes (Cowen et al., 2000)

Sabendo que os produtos naturais têm contribuído significativamente na descoberta de estruturas químicas para fabricação de novos fármacos que serão usadas como agentes inovadores na terapêutica de doenças muito prevalentes, como é o caso da Candidíase, têm-se buscado cada vez mais recursos alternativos para o tratamento e controle da mesma (Neet 2014). Neste sentido, verificou-se que entre 1981 e 2010 diversas drogas de origem natural revelaram potencial terapêutico contra diversas espécies de fungos (Newman \& Crag 2012).

Dentro desse contexto, cresce o interesse por produtos naturais que apresentem atividade antibacteriana e antifúngica seletiva de forma a evitar e tratar doenças bucais, com o mínimo de efeitos adversos e o máximo de efetividade para os seus usuários. (Galvão et al., 2012)

Assim espécie Arrabidaea chica Verlot (A. chica), conhecida popularmente por "Pariri", "Crajiru", "Carajuru" ou "Carajiru" (Van Den Berg 1993), foi selecionada para ser o objeto de estudo deste trabalho. É uma planta pertencente à relação nacional de plantas medicinais de interesse ao sistema único de saúde (Ministério da Saúde 2006) e nativa da região amazônica, sendo encontrada também em todas as regiões tropicais da América do Sul e África (Dévia et al., 2002).

Na região amazônica, é utilizada como chá, feito a partir de suas folhas para tratar inflamação da pele, distúrbios gastrointestinais, melena, enterocolite, leucemia, anemia e albuminúria (Aro et al., 2012). É utilizada até os dias atuais pelos índios desta região, que fazem uma decocção das folhas para a realização de limpeza de feridas crônicas e tratamento de infecções fúngicas e herpes (Lorenzi \& Matos 2008).

$\mathrm{Na}$ literatura, diversos efeitos biológicos e farmacológicos da A. chica foram relatados, tendo destaque o seu potencial antimicrobiano demonstrando ação antifúngica contra algumas espécies de Candida (Hofling et al., 2010, Mafioletiet et al., 2013, Wiziack Zago et al., 2020), eficácia quando utilizada na cicatrização de feridas, efeito anti-inflamatório e atividade antioxidante (Giordani et al., 2015, Jorge et al., 2008, Medeiros et al., 2011, Aro et al., 2012, Oliveira et al., 2009), sendo utilizada geralmente na forma de extrato hidroalcoólico (Santos et al., 2013) ou diclorometano (Hofling et al., 2010).

Diante desses achados e frente à busca por uma possível substância de imersão para próteses dentárias com potencial antifúngico e que cause menos efeitos deletérios, este estudo teve como objetivo investigar a ação do extrato hidroálcoolico de 
A. chica contra Candida albicans em estado planctônico e na forma de biofilme, bem como a citotoxicidade do extrato em fibroblastos e queratinócitos e a sua capacidade de alterar as propriedades físico/mecânicas de resina de polimetilmetacrilato (PMMA).

\section{Metodologia}

\subsection{Material Vegetal e extrato hidroalcóolico da A. Chica}

As folhas de A. chica Verlot Bignoniaceae foram coletadas no campo experimental do Centro Pluridisciplinar de pesquisas Químicas, Biológicas e Agrícolas (CPQBA) da Universidade Estadual de Campinas $\left(22^{\circ} 45^{\prime} 00^{\prime \prime}\right.$ sul e $47^{\circ} 10^{\prime} 21^{\prime \prime}$ oeste; Paulinia, Brasil) e fazem parte de um banco de Germoplasmas (excicata 1865). A espécie estudada. foi depositado no herbário do CPQBA e cadastrada sob o número de voucher correspondente (1348). O número de autorização de acesso ao patrimônio genético foi emitido pelo Conselho Nacional para o Desenvolvimento Científico e Tecnológico (CNPq), CGen/MMA, para este estudo.

O extrato padronizado hidroalcoólico de A. chica (AchE) foi obtido pelo método descrito anteriormente por Jorge et al (2008) com modificações. Um quilo de folhas secas e moídas foi utilizado para confeção do extrato, utilizando 5L de mistura acidificada (0,3\% de ácido cítrico) de solução de hidroalcoólica a 70\% durante uma hora e meia, à temperatura ambiente, por maceração. Este procedimento foi repetido por três vezes. Após a filtração, o solvente orgânico foi evaporado usando vácuo e a água residual foi removida por secagem por pulverização (Mini Spray Dryer B-290, alça B-295; Büchi®, Suíça) com temperatura de entrada $100^{\circ} \mathrm{C} \pm 2^{\circ} \mathrm{C}$ e temperatura de saída de $60^{\circ} \mathrm{C} \pm 2^{\circ} \mathrm{C}$, aspiração de $250 \mathrm{~mL} / \mathrm{h}$ de $\mathrm{N}_{2}$ ambiente não filtrado, pressão de injeção de $414 \mathrm{~L} / \mathrm{h}$ e fluxo de alimentação de $5 \mathrm{~mL} / \mathrm{min}$ à temperatura ambiente, produzindo o produto final. O resíduo seco foi diluído em dimetilsulfóxido (DMSO 2\%) até uma concentração final de $5.000 \mu \mathrm{g} / \mathrm{mL}$, filtrado em membrana de $0,22 \mu \mathrm{g} / \mathrm{mL}$ e mantidos em frascos âmbar até a realização dos experimentos.

\subsection{Análises químicas}

A caracterização química do extrato foi feita de acordo com o método descrito por Wen et al., (2005) por Cromatografia Líquida de Alta Eficiência (CLAE) usando um sistema LC-10AD (Shimadzu, Japão) equipado com detector de diodos (DAD) e acoplado a um espectrômetro de massas Esquire 3000 Plus (Bruker Daltonics, Bremen, Alemanha), usando ionização por electrospray (ESI). Foi realizada a separação com coluna Phenomenex Kinetex C-18 $(250 \times 4,6 \mathrm{~mm}, 5 \mu \mathrm{m}$; Torrance, CA, EUA). Foram utilizados ácido fosfórico e metanol como fases móveis A e B, respectivamente. A preparação do gradiente de eluição foi realizada da seguinte forma: 5-20 min de 55 a 10\% A, e depois durante 20-30 min de 10 a 0\% A. O volume de injeção consistiu de $20 \mu \mathrm{L}$ de amostra reconstituída e taxa de fluxo de $1 \mathrm{~mL} / \mathrm{min}$. Para a detecção utilizou-se um DAD a $470 \mathrm{~nm}$ e um método de espectrometria de massa direta (-ESI) com a voltagem mantida em $4,0 \mathrm{kV}$, fonte de íons de 40 $\mathrm{V}$ e temperatura capilar de $320^{\circ} \mathrm{C}$. Identificou-se os compostos com base no tempo de retenção e massa molecular.

\subsection{Preparo da suspensão de C. albican}

Colônias de C. albicans foram reativadas em meio de cultura a base de nitrogênio de levedura (YNB) (Himedia, Mumbai, India) suplementado com 50mM de glicose. Colônias de C. albicans foram coletadas a partir de placas de Sabouraud Dextrose Agar (Himedia,Mumbai, India) e foram resuspensas em $50 \mu \mathrm{L}$ do meio de YNB , em seguida foram encubadas por $24 \mathrm{~h}$ à $37^{\circ} \mathrm{C}$. As células foram centrifugadas $(1200 \mathrm{rpm}, 10$ minutos, $10 \circ \mathrm{C})$, lavadas duas vezes com tampão fosfato $0.15 \mathrm{M}(\mathrm{pH}$

7.2, $\mathrm{Ca}^{2+-}$ e livre de $\mathrm{Mg}_{2}$ ), resuspensas em $40 \mathrm{~mL}$ de PBS, e a sua absorbância foi lida em espectrofotômetro até se obter uma concentração de $5 \times 10^{6} \mathrm{UFC} / \mathrm{mL}(530 \mathrm{~nm}, \lambda=0.08-0.1$ ) (Kuhn et al., 2002). 


\subsection{Determinação da Concentração Inibitória Mínima e Fungicida Mínima (CIM/CBM)}

O ensaio de CIM foi realizado para avaliar a susceptibilidade das células planctônicas de C. albicans ao extrato de $A$. chica, em placas de 96 poços de fundo chato e com meio de cultura RPMI (Sigma-Aldrich, St. Louis, MO, USA), 100 $\mu \mathrm{L} /$ poço. $100 \mu \mathrm{L}$ da solução stock do AchE foi transferida ao primeiro poço da placa de 96 poços e foi realizada a sua diluição seriada de forma a se obter o AchE nas concentrações 1,000 a $0.48 \mu \mathrm{g} / \mathrm{ml}$. Nistatina (Sigma-Aldrich, St. Louis, MO, USA), Anfoterinina B (União Química Farmacêutica Nacional, SP, Brasil), e DMSO 2 \% (veículo, v/v) (Gonçalves et al., 2019) foram utilizados como controles positivos e negativo, respectivamente. O meio de cultura estéril, o AchE, e a viabilidade do fungo também foram testadas. O inóculo fúngico foi preparado de acordo com o item 2.3 (530 nm, abs 0.08-0.1) e diluído até a concentração final de $2.5 \times 10^{3} \mathrm{UFC} / \mathrm{mL}$ em cada poço. As placas foram incubadas à $37^{\circ} \mathrm{C}$ por $24-48 \mathrm{hrs}$. A CIM foi definida como a menor concentração do AchE que inibiu visivelmente o crescimento fúngico (Freires et al., 2015).

CFM foi determinada pelo plaqueamento de alíquotas dos poços onde não houve crescimento fúngico visível, ou seja, dos poços com concentração maior ou igual à CIM, em placas de ágar Sabouraud Dextrose (HIMEDIA Laboratories Pvt. Ltd., Mumbai, India), as quais foram incubadas à $37^{\circ} \mathrm{C}$ por $48-72 \mathrm{hrs}$. CFM foi definida como a menor concentração do AchE que impediu o crescimento fúngico ( $\geq 99.9 \%$ ) em meio sólido (Freires et al., 2015).

Para determinar a natureza do efeito antifúngico do AchE, a razão CFM: CIM foi determinada Galvão et al., 2012). Quando a razão CFM: CIM foi de 1: 1 ou 2: 1, o extrato em questão é considerado bactericida contra o microrganismo estudado, e quando a razão for maior que 2: 1, o extrato é considerado bacteriostático.

\subsection{Preparo dos discos de resina acrílica de PMMA}

Discos circulares (10 mm de diâmetro x 2 mm de espessura) de resina a base de PMMA (JET, Clássico, São Paulo, SP, Brasil) $(n=45)$ foram confeccionados com uma matriz metálica com as respectivas dimensões para padronização dos discos. A proporção de pó e líquido, bem como a manipulação da resina acrílica, prensagem e imersão em água fervente seguiu as instruções do fabricante (imersão em água a $73^{\circ} \mathrm{C}$ por 90 min e fervura por $30 \mathrm{~min}$ ). Os discos então foram imersos em água destilada a $37^{\circ} \mathrm{C}$ por $48 \mathrm{~h}$ de modo a permitir a lixiviação de monômeros residuais (Moura et al., 2006). Os discos receberam acabamento com lixas sequenciais acopladas na politriz (Arotec, Cotia, SP, Brasil) sob irrigação (\#320, \#400 e \#600) por 60 segundos cada lixa (Wieckiewicz et al., 2014), padronizando-se valor inicial de Ra $=0,13 \pm 0,03 \mu \mathrm{m}$.

\subsection{Desenvolvimento e análise dos biofilmes}

Para a formação do biofilme, foram alocados em placa de 24 poços, discos de resina acrílica $(n=45)$. Estes foram expostos ao inóculo de $C$. albicans previamente ajustado seguido da incubação das placas sob agitação constante, a $37^{\circ} \mathrm{C}$, por $90 \mathrm{~min}$, (fase de adesão celular). Posteriormente, os discos foram transferidos para poços compostos por meio Sabouraud suplementado com sacarose $2 \%$ e mantidos por 24 horas a $37^{\circ} \mathrm{C}$ para que o biofilme fosse desenvolvido, repetindo-se o processo até o biofilme completar 48 horas. Em seguida, o biofilme foi imerso por 8 horas nos tratamentos: tampão fosfatosalino (PBS, controle negativo), hipoclorito de sódio 1\% (NaOCl 1\%, controle positivo) ou AchE na CIM, 5xCIM ou 10xCIM. A contagem celular foi realizada através de diluição decimal seriada e para tal, o biofilme desenvolvido sobre os discos de resina foram sonicados (7 Watts, $30 \mathrm{~s}$ ) em solução salina para que ocorresse a desagregação celular. Submeteu-se então a suspensão obtida à diluição decimal seriada, e o produto de cada diluição foi inoculado em placas de ágar Sabouraud Dextrose (HIMEDIA Laboratories Pvt. Ltd., Mumbai, India) em triplicata. As placas foram incubadas a $37^{\circ} \mathrm{C}$ por 24 horas e as colônias foram quantificadas de forma visual. $\mathrm{O}$ resultado foi apresentado em células $/ \mathrm{mL}$. 


\subsection{Citotoxicidade}

Foi realizado o ensaio de citotoxicidade seguindo a padronização (ISO 10993). Fibroblastos murinos de linhagem comercial NIH 3T3 (American Type Culture Collection - ATCC CRL-1658TM - Rockville, MD, EUA) e queratinócitos humanos HaCaT (Cell Lines Service - CLS 300493, Alemanha) foram mantidos em estufa a $37^{\circ} \mathrm{C}$ e $5 \% \mathrm{CO}_{2}$ em atmosfera úmida, e cultivadas em meio de cultura Dulbecco's Modified Eagle's Medium (DMEM - Gibco, Invitrogen Corporation, Carlsbad, CA, EUA) enriquecido com 10\% de soro fetal bovino (SFB; Atlanta biologicals ${ }^{\circledR}$ ), 100 U/mL de penicilina, 100 $\mu \mathrm{g} / \mathrm{mL}$ de estreptomicina e $250 \mathrm{ng} / \mathrm{mL}$ Fungizone (anfotericina B; Gibcoß) (Jorge 2008). O teste consistiu na inoculação das células ( $4 \times 10^{4}$ células $/ \mathrm{mL}$ ) em placa de 96 compartimentos (K12-096, KASVI, China).

Após $24 \mathrm{~h}$ de incubação $\left(37^{\circ} \mathrm{C}, 5 \%\right.$ de $\left.\mathrm{CO}_{2}\right)$, todo o meio dos poços contendo as células foi aspirado para adição de novo meio DMEM 5\% SFB contendo as soluções testadas neste estudo AcHE a $10 \mu \mathrm{g} / \mathrm{mL}$ (AchE10), $50 \mu \mathrm{g} / \mathrm{mL}$ (AcHE50) e $100 \mu \mathrm{g} / \mathrm{mL}$ (AcHE100), PBS e NaOCl. As placas foram novamente incubadas por $48 \mathrm{~h}\left(37^{\circ} \mathrm{C}, 5 \%\right.$ de $\mathrm{CO}_{2}$ ). Ao final de $48 \mathrm{~h}$, todo meio foi aspirado e substituído por novo meio de cultura contendo DMEM/SFB acrescido de MTT [bromídeo de 3-(4,5dimetiltiazol-2-yl)-2,5-difenil-tetrazólio 0,5\%]. As placas foram incubadas por $4 \mathrm{~h}\left(37^{\circ} \mathrm{C}, 5 \% \mathrm{de} \mathrm{CO}_{2}\right)$. Depois desse período, o meio foi solubilizado por DMSO a 100\% (100 $\mu \mathrm{L} /$ poço) e a leitura espectrofotométrica foi realizada a $570 \mathrm{~nm}$. A partir dos valores de absorbância obtidos, foram calculadas as porcentagens de viabilidade celular. O cálculo considerou: \% Viabilidade = TA / T1 x100 (onde: TA = média da absorbância da célula tratada - absorbância do branco da amostra; T1 = absorbância da suspensão celular sem tratamento).

\subsection{Efeito nas propriedades físico/mecânicas da resina acrílica (PMMA)}

Discos de PMMA $(\mathrm{n}=45)$ foram distribuídos aleatoriamente entre os 5 grupos de tratamento (água destilada, $\mathrm{NaOCl}$ 1\%, AchE na CIM, 5xCIM ou 10xCIM). Os discos foram incubados a $37^{\circ} \mathrm{C}$ durante 28 dias. O meio de imersão foi trocado diariamente. Após, os discos foram lavados em água destilada e secos em papel absorvente. Os testes foram realizados após 0 , 7, 14, 21 e 28 dias de imersão.

A análise de rugosidade foi realizada com um rugosímetro (Surftest SJ-201P, Mitutoyo, Japão). Para cada disco, três leituras foram realizadas a uma velocidade de $5 \mathrm{~mm} / \mathrm{s}$. A rugosidade de cada disco foi calculada usando a média aritmética das três medições $(\mathrm{Ra})$ em micrômetros $(\mu \mathrm{m})$. A alteração da rugosidade de superfície $(\Delta \mathrm{Ra})$ foi obtida pela diferença entre a rugosidade após imersão e valores iniciais de rugosidade (baseline). (Golçalves et al., 2019)

Para a percepção de alteração de cor, os discos foram posicionados em um molde confeccionado em silicone com uma abertura destinada a permitir o contato do disco a um espectrofotômetro portátil Easyshade (Vita, Wilcos, Alemanha). Este molde foi utilizado para reposicionar com precisão os discos e medir as cores da superfície de cada um. A alteração de cor total $(\Delta \mathrm{E})$ foi calculada a partir da seguinte equação: $\Delta \mathrm{E} *=\left[\left(\Delta \mathrm{L}^{*}\right)^{2}+\left(\Delta \mathrm{a}^{*}\right)^{2}+(\Delta \mathrm{b} *)^{2}\right]$. Valores de $\Delta \mathrm{E}<3.7$ foram considerados como clinicamente imperceptíveis (Madeira et al., 2016).

Para o teste de resistência flexural, espécimes retangulares $(\mathrm{n}=125,65 \times 10 \times 3 \mathrm{~mm})$ foram confeccionados com o auxílio de uma matriz metálica, com a mesma resina acrílica (PMMA) seguindo as orientações do fabricante (descritos anteriormente). Os espécimes foram aleatorizados entre as condições experimentais previamente descritas (Madeira, et al 2016). A resistência flexural foi realizada utilizando o teste de três pontos em uma máquina de ensaio universal (DL 2000, EMIC, São José dos Pinhais, PR, Brasil). O teste foi aplicado a uma distância de $50 \mathrm{~mm}$ entre os dois pontos de suporte, no centro do espécime com uma célula de carga de $50 \mathrm{kgf}$. Os valores obtidos foram submetidos à seguinte fórmula de resistência flexural: $\mathrm{S}=3 P L / 2 b d^{2}$, em que $\mathrm{S}$ é resistência flexural, $P$ é carga máxima aplicada, $L$ é comprimento da distância entre os dois pontos, $b$ é largura do espécime e $d$ é espessura do espécime (\&). 


\subsection{Análise estatística}

Os resultados foram analisados estatisticamente pelo software SAS/LAB (SAS Software, versão 9.0; SAS Institute Inc., Cary, NC, EUA). A distribuição normal dos dados foi previamente ajustada e, quando necessário, os dados foram transformados conforme sugerido pelo software. Os dados referentes à contagem de células, atividade metabólica e viabilidade de queratinócitos e fibroblastos foram analisados pelo teste ANOVA one-way seguido do teste de Tukey, no qual o tratamento por imersão foi tratado como fator de estudo. Os dados de alteração de cor e rugosidade de superfície foram analisados por ANOVA two-way para medidas repetidas, seguido pelo teste de Tukey, no qual os períodos de tratamento e o tipo de imersão foram considerados fatores de estudo. O nível de significância foi estabelecido em 5\% para todos os testes.

\section{Resultados}

\subsection{Rendimento do AchE e Caracterização química}

O AchE padronizado apresentou pH $4.88 \pm 0.02$. Foram encontrados os compostos majoritários 6,7,3',4'-tetrahydroxy5-methoxyflavylium, 6,7,4'-trihydroxy-5-methoxyflavylium, e carajurin após análise por HPLCDAD que podem justificar a atividade do AchE. O conteúdo de carajurin no AchE representa 6.51\% $\pm 0.07 \%$ do seu total (Wiziack Zago et al., 2020)

\subsection{Atividade antimicrobiana}

Os valores da CIM e CFM para o AchE contra a C. albicans foram entre125 to $250 \mu \mathrm{g} / \mathrm{mL}$ (Tabela 1). E a razão CFM: CIM de 1:1 mostram que o AchE tem potencial bactericida.

\subsection{Atividade do AchE contra o biofilme de C. albicans}

Para os biofilmes de C. albicans, a exposição ao AchE por 8 horas teve efeito significativo, reduzindo a contagem de células quando comparado ao controle negativo ( $p=0.001$. O AchE na CIM foi suficiente para reduzir aproximadamente $80 \%$ das células do biofilme $(p<0.0001)$. Quando os biofilmes de $C$. albicans foram expostos ao AchE 5xCIM alcançou-se quase uma completa erradicação do biofilme deste microrganismo (> 99\%), semelhante ao resultado obtido com $\mathrm{NaOCl} 1 \%$ (controle positivo, $p>0.05)$.

\subsection{Citotoxicidade}

Considerando fibroblastos, maior viabilidade celular foi detectada para os grupos tratados com PBS e AcHE10, os quais foram estatisticamente similares entre si $(p>0,05)$ e considerados não-citotóxicos. Os grupos AcHE50 e AcHE100 foram semelhantes estatisticamente $(p>0,05)$ e apresentaram-se entre moderadamente e severamente tóxicos $(p<0,05)$. Já o grupo HS1\% foi severamente tóxico ( $p<0,0001)$ (Figura 1).

Em relação à viabilidade celular de queratinócitos, também houve diferença estatisticamente significante entre todos os grupos experimentais ( $p<0,0001)$. O grupo AcHE10 não foi tóxico $(p<0,0001)$, com valores comparados ao grupo PBS ( $p$ $>0,05)$. Os grupos AcHE50 e AcHE100 mostraram resultados semelhantes estatisticamente $(p>0,05)$ e foram considerados severamente tóxicos $(p<0,0001)$. HS1\% foi severamente tóxico $(p<0,0001)$ (Figura 1). 
Figura 1. Avaliação da citotoxicidade do AchE em diferentes concentrações na viabilidade celular (\%) de fibroblastos e queratinócitos, pelo método MTT.



Fonte: Autores.

\subsection{Efeito nas propriedades físico/mecânicas da resina acrílica}

Quanto aos efeitos na rugosidade, todos os grupos de tratamento foram semelhantes estatisticamente ao longo dos 28 dias de tratamento $(p>0,05)$ (Tabela 1$)$.

Tabela 1. Média e desvio-padrão obtidos das análises da rugosidade $(\mu \mathrm{m})$ dos 5 grupos teste nos tempos avaliados.

\begin{tabular}{c|ccc}
\hline Grupo & Imediato & $\mathbf{1 4}$ dias & 28 dias \\
\hline Controle & $0,12 \pm 0,03$ & $0,13 \pm 0,02$ & $0,10 \pm 0,02$ \\
$\mathrm{NaOCl}$ & $0,16 \pm 0,04$ & $0,15 \pm 0,02$ & $0,10 \pm 0,01$ \\
$\mathrm{AcHE} 10$ & $0,13 \pm 0,02$ & $0,12 \pm 0,05$ & $0,10 \pm 0,05$ \\
AcHE50 & $0,11 \pm 0,04$ & $0,13 \pm 0,02$ & $0,13 \pm 0,08$ \\
AcHE100 & $0,14 \pm 0,05$ & $0,14 \pm 0,04$ & $0,12 \pm 0,03$
\end{tabular}

ANOVA: entre grupos $p=0,200$; entre tempos $p<0,001 *$; interação $p=0,034^{*}$. Fonte: Autores.

Em relação à percepção na alteração da cor, não houve diferença estatisticamente significativa entre os grupos de tratamento $(p>0,05)$ independente do tempo avaliado (Tabela 2). Apesar dos grupos AcHE10 e AcHE100 apresentarem respectivamente menores e maiores valores de $\Delta \mathrm{E}$, essa alteração não foi significante, visto que, uma diferença de cor $<3.7$ é relatada como clinicamente imperceptível (Mon et al., 2014). 
Tabela 2. Média e desvio-padrão obtidos das análises da alteração de cor $(\Delta \mathrm{E})$ dos 5 grupos nos tempos avaliados.

\begin{tabular}{c|cc}
\hline \multicolumn{1}{c}{ Grupo } & $\mathbf{1 4}$ dias & 28 dias \\
\hline Controle & $1,57 \pm 0,75$ & $1,41 \pm 0,62$ \\
NaOCl & $1,67 \pm 0,67$ & $2,11 \pm 1,37$ \\
AcHE10 & $0,80 \pm 0,56$ & $1,35 \pm 0,50$ \\
AcHE50 & $3,30 \pm 1,44$ & $2,35 \pm 1,86$ \\
AcHE100 & $3,40 \pm 0,73$ & $3,13 \pm 1,13$ \\
\hline
\end{tabular}

ANOVA: entre grupos $\mathrm{p}=0,051$; entre tempos $\mathrm{p}=0,684$; interação $\mathrm{p}=0,509$.

Fonte Autores.

Não houve diferença estatisticamente significante entre os grupos de tratamento no teste de resistência flexural ( $p>$ ANOVA: entre grupos $p=0,200$; entre tempos $p<0,001 *$; interação $p=0,034 * .0,05$ ) independente do tempo avaliado (Tabela 3).

Tabela 3. Média e desvio-padrão obtidos das análises da resistência flexural (MPa) para todos os grupos experimentais . ANOVA-2 fatores medidas repetidas.

\begin{tabular}{|c|c|c|c|}
\hline Grupo & Imediato & 14 dias & 28 dias \\
\hline Controle & $60,73 \pm 6,83$ & $62,75 \pm 7,09$ & $72,83 \pm 10,12$ \\
\hline $\mathrm{NaOCl}$ & $67,84 \pm 12,62$ & $62,53 \pm 19,77$ & $59,77 \pm 7,64$ \\
\hline$A C 10$ & $63,04 \pm 13,63$ & $59,78 \pm 3,58$ & $70,34 \pm 11,69$ \\
\hline$A C 50$ & $67,33 \pm 4,99$ & $73,46 \pm 8,43$ & $69,51 \pm 7,10$ \\
\hline AC100 & $65,40 \pm 9,10$ & $57,35 \pm 10,77$ & $69,07 \pm 9,24$ \\
\hline
\end{tabular}

ANOVA-2 fatores medidas repetidas. Fonte Autores.

\section{Discussão}

No mercado, existem diversos medicamentos e protocolos de higienização para o controle de infecções de próteses dentárias por C. albicans, no entanto, além de serem potencialmente tóxicos (Correa et al 2018), podem causar efeitos deletérios (Little \& Falace 1987), ou ainda, falhar na remoção do biofilme (Cowen et al., 2000). Devido a esses fatores, novas terapias devem ser sugeridas a fim de controlar a CAP, minimizando as desvantagens dos produtos disponíveis no mercado.

Neste sentido, pesquisas envolvendo compostos com propriedades antifúngicas de origem natural vêm aumentando (Gonçalves et al., 2019), inclusive na Odontologia. Desta forma, neste estudo, foi investigado e descrito pela primeira vez na literatura o efeito do extrato de A. chica em biofilmes de $C$. albicans sobre superfícies de resina acrílica, simulando a condição de biofilme na superfície de próteses dentais removíveis. Buscando investigar o potencial da $A$. chica como método auxiliar no controle da CAP, avaliou-se o efeito anti-biofilme, a toxicidade em queratinócitos e fibroblastos, e os possíveis efeitos deletérios causados sobre a resina acrílica pelo extrato.

Através da caracterização química da A. chica foi possível identificar com grande abundância os 6,7,3',4'tetrahydroxy-5-methoxyflavylium, 6,7,4'-trihydroxy-5-methoxyflavylium, e carajurin, compostos pertencentes ao grupo dos flavonóides, similar ao que já foi descrito na literatura (Wen et al., 2005). Os flavonóides apresentam diversas atividades farmacológicas, entre estas, potencial antimicrobiano e antioxidante. Estes compostos estão relacionados com a inativação de enzimas responsáveis pela adesão celular, o que provavelmente funciona como seu mecanismo de ação antimicrobiana. Além disso, sabe-se que os flavonóides têm potente ação antioxidante, o que explica sua capacidade de regular o sistema imune. A 
quercetina e o kaempferol já tiveram sua atividade antimicrobiana atestada contra Staphylococcus aureus, Escherichia coli, Enterococcus faecalis, Pseudomonas aeruginosa, Ptroteus mirabilis e C. albicans.

Como ponto de partida para os testes em C. albicans, foi avaliada a susceptibilidade das células planctônicas ao extrato de A. chica. Através deste teste, foram observados valores coincidentes de CIM e CFM (entre 125 e $250 \mu \mathrm{g} / \mathrm{mL}$ ), evidenciando o potencial fungicida do extrato. De acordo com Aligiannis et al., 2001 e Galvao et al., 2012, existe uma classificação para os produtos naturais baseada nos valores de CIM, sendo fortes inibidores os produtos cuja CIM seja menor que $500 \mu \mathrm{g} / \mathrm{mL}$; inibidores moderados os prosutos cuja CIM esteja entre 600 e $1500 \mu \mathrm{g} / \mathrm{mL}$; e fracos inibidores os produtos naturais cuja CIM esteja acima de $1600 \mu \mathrm{g} / \mathrm{mL}$.

Desta forma, o AchE pode ser considerado um forte inibidor de C. albicans, uma vez que inibiu seu crescimento com valores de CIM $\leq 500 \mu \mathrm{g} / \mathrm{mL}$. Além disso, o valor de CIM encontrado neste estudo corrobora com os encontrados na literatura. Hofling et al 2010 avaliaram o extrato de A. chica verlot na inibição de diversas espécies de Candida. Por meio da análise CIM até mesmo em baixas concentrações (de 1 até $7 \mu \mathrm{g} / \mathrm{mL}$ ) o extrato demonstrou atividade antifúngica para todas as espécies, apresentando efeito inibitório contra $C$. albicans quando utilizado em concentrações mais altas.

É importante frisar que os valores de CIM são obtidos em testes que avaliam a C. albicans em sua forma planctônica. $\mathrm{Na}$ cavidade oral, em especial, na superfície da prótese, estas células estão organizadas em biofilmes que, por sua complexidade estrutural, são relativamente mais resistentes à atuação de agentes antifúngicos. Por este motivo, neste estudo, o efeito antifúngico do AchE foi avaliado em biofilmes de C. albicans maduros (i.e. 48 horas de desenvolvimento), e o tempo de imersão de 10 minutos foi escolhido em função do tempo recomendado de imersão para o grupo controle positivo, o $\mathrm{NaOCl}$ $1 \%$.

Para o biofilme de $C$. albicans, foi possível observar que 10 minutos de imersão no AchE na CIM foi suficiente para reduzir o número de células do biofilme comparado ao grupo controle. Estes resultados podem ser atribuídos à presença da quercetina e do kaempferol na sua composição química, os quais apresentam potencial antifúngico reconhecido. Além de interferir diretamente no primeiro mecanismo de virulência do fungo, ou seja, a adesão celular (ISO 10993-5), estes compostos também podem impedir o transporte de proteínas e ocasionar a ruptura da célula fúngica.

Uma grande redução da viabilidade e atividade fúngica foi observada nos biofilmes expostos ao AchE 5xCIM, apresentando uma tendência fungicida similar ao que foi encontrado no grupo com $\mathrm{NaOCl} 1 \%$. Tais resultados podem ser consequência da desagregação das células e inibição da capacidade de aderência. Ainda, é possível que a redução da atividade metabólica possa ter ocorrido devido ao estresse intracelular decorrente da ação do extrato quando em maior concentração (Aro et al., 2013).

Levando em consideração o íntimo contato entre a prótese dental removível e os epitélios orais, os possíveis efeitos tóxicos do AchE nestes tipos celulares devem ser avaliados, garantindo segurança em estudos clínicos futuros. De acordo com a International Standard Organization (ISO 10993-5), concentrações em que a viabilidade celular se mantem menor que 70\%, pode ser considerada citotóxica. Dessa forma, foi observado que o AchE foi menos citotóxico aos fibroblastos e queratinócitos quando comparado ao grupo $\mathrm{NaOCl} \%$, solução mais comumente indicada para higiene de próteses totais e parciais removíveis (Orsi et al., 2011, Webb et al., 2013). Entretanto, apenas o grupo AcHE10 foi considerado não-citotóxico. Os grupos AcHE50 e AcHE100 foram considerados severamente citotóxicos, visto que, promoveram viabilidade celular menor que 50\% (ISO 10993-5). Em estudo anterior (Jorge et al., 2008) o extrato de A. chica verlot foi avaliado em diversas concentrações variando de 0,25 a $250 \mu \mathrm{g} / \mathrm{mL}$ em fibroblastos e, além de ter demonstrado ser viável em todas as concentrações, estimulou síntese de colágeno. Neste mesmo estudo, concentrações mais elevadas (até $100 \mathrm{mg} / \mathrm{mL}$ ) foram avaliadas in vivo em ratos, e em até 100 $\mathrm{mg} / \mathrm{mL}$ o extrato demonstrou segurança em ser utilizado com potencial cicatrizador. Os resultados distintos encontrados sugerem que as diferentes metodologias aplicadas nos estudos podem interferir nos resultados. 
Considerando as propriedades físico/mecânicas, estudos (Felipucci et al., 2011, Paranhos et al., 2013, Porta et al., 2015) demonstraram que a imersão e algumas soluções químicas pode alterar a rugosidade da superfície, a cor bem como a resistência flexural de resinas PMMA. Essas alterações interferem diretamente na estética e longevidade das próteses dentárias.

Neste estudo não foram encontradas alterações nas propriedades físico/mecânicas testadas em comparação aos grupos controle e HS1\% ao longo dos 28 dias de imersão. Apesar de 28 dias de imersão parecer ser um curto período de tempo quando comparado à vida útil de uma prótese dentária, a exposição constante às soluções é capaz de envelhecer de forma significativa a matriz acrílica, criando uma situação desafiadora para o material testado (Madeira et al., 2016).

O aumento da rugosidade superficial facilita o acúmulo de biofilme na superfície acrílica (Al-Dwairi et al., 2012). O resultado mostrou-se favorável, ao demonstrar que, mesmo na concentração mais elevada testada, não alterou de forma significante a rugosidade superficial dos discos. Já considerando a alteração de cor, apesar de o extrato de A. chica apresentar maiores valores na mais alta concentração testada, ele não foi capaz de impregnar na matriz acrílica, não causando diferenças estatisticamente significantes quando comparado aos demais grupos testados, inclusive ao HS1\%. Além disso, não foram encontradas diferenças clinicamente perceptíveis, visto que, uma diferença de cor <3.7 é relatada como clinicamente imperceptível (Moon et al., 2014). Apesar do HS1\% ser uma solução química com propriedade branqueadora, neste estudo, ele não foi capaz de alterar a coloração da resina acrílica. Estudo anterior (Heidrich et al., 2018) encontraram alteração de cor em todos os grupos de seu estudo quando espécimes de resina acrílica eram imersos em outros extratos (óleo de rícino, óleo de alecrim, extrato glicólico de própolis), bem como em água destilada e hipoclorito de sódio, porém por maior período de tempo que neste trabalho. Nossos diferentes achados podem se relacionar com o menor tempo de imersão utilizado e o fenômeno de sorção de água que a resina acrílica apresenta quando imersa em água por longos períodos (Fernandes et al., 2011).

Com relação à resistência flexural da resina acrílica, os resultados sugerem que, mesmo quando imersa em diferentes concentrações, o extrato de A. chica não foi capaz de alterar esta propriedade. Este é um aspecto favorável, visto que, uma possível redução da resistência aumenta as chances de fratura da resina (Porta et al., 2015, Al-Dwairi et al., 2012), demonstrando uma vantagem no uso deste extrato.

\section{Conclusão}

O AchE apresenta compostos que justificam sua atividade antimicrobiana como um forte agente antifúngico sendo capaz de inibir o crescimento de C. albicans em estado planctônico e na forma de biofilme. Ao mesmo tempo, quando utilizado em concentrações a partir de $50 \mu \mathrm{g} / \mathrm{mL}$, torna-se citotóxico em fibroblastos e queratinócitos e, independente das concentrações utilizadas, não interferiu nas propriedades físico/mecânicas das resinas PMMA.

Vislumbrando trabalhos futuros, pretende-se continuar com a caracterização química e biológica do extrato de Arrabidaea chica, prosseguindo com o seu fracionamento químico de forma a tentar concentrar, em uma fração, o(s) composto(s) químico(s) de melhor atividade contra Candida albicans, e assim combater de maneira mais eficiente a CAP com o mínimo de efeitos adversos.

\section{Referências}

Al-Dwairi, Z. N., Al-Quran, F. A. \&Al-Omari, O. Y. (2012). The effect of antifungal agents on surface properties of poly(methylmethacrylate) and its relation to adherence of Candida albicans. J Prosthodont Res. 56:272-280. https://doi.org/10.1016/j.jpor.2012.02.006.

Aligiannis, N., Kalpotzakis, E., Mitaku, S. \& Chinou, I. B. (2001). Composition and antimicrobial activity of the essential oils of two Origanum species. Journal of Agricultural and Food Chemistry. 40:4168-4170. https://doi.org/10.1021/jf001494m.

Aro, A. A., Simões, G. F., Esquisatto, M. A. M., Foglio, M. A., Carvalho, J. E., Oliveira, A. L. R., Gomes, L. \& Pimentel, E. R. (2012). Arrabidaea chica extract improves gait recovery and changes collagen content during healing of the Achilles tendon. Injury. 44:884-892. https://doi.org/10.1016/j.injury.2012.08.055. 
Aro, A. A., Freitas, K. M., Foglio, M. A., et al (2013). Effect of the Arrabidaea chica extract on collagen fiber organization during healing of partially transected tendo. Life Sci. 93(13):799-807. https://doi.org/10.1016/j.lfs.2013.02.011.

Correa, R. M. S., Mota, T. C., Guimarães, A. C., Bonfim, L. T., Burbano, R. R. \& Bahia, M. O. (2018). Cytotoxic and genotoxic effects of fluconazole on african green monkey kidney (vero) cell line. Biomed Res Int. 2018:1-7. https://doi.org/10.1155/2018/6271547.

Cowen, L. E., Sanglard, D., Calabrese, D., Sirjusingh, C., Anderson, J. B. \& Kohn, L. M. (2000). Evolution of drug resistance in experimental populations of Candida albicans. J Bacteriol. 182:1515-1522. https://doi.org/10.1128/JB.182.6.1515-1522.2000.

Devia, B., Llabres, G., Wouters, J., Dupont, L., Escribano-Bailon, M. T., Pascual-Teresa, S., Angenot, L. \& Tits, M. (2002). New 3-deoxyanthocyanidins from leaves of Arrabidaea chica. Phytochemical Analyss. 13:114-120. https://doi.org/10.1002/pca.632

El Bahra, S., Ludwig, K., Samran, A., Freitag-Wolf, S. \& Kern, M. (2013). Linear and volumetric dimensional changes of injection-molded PMMA denture base resins. Dent Mater 29:1091-1097. https://doi.org/10.1016/j.dental.2013.07.020.

Felipucci, D. N., Davi, L. R., Paranhos, H. F., Bezzon, O. L., Silva, R. F., Barbosa Júnior, F. \& Pagnano V. O. (2011). Effect of different cleansers on the weight and ion release of removable partial denture: an in vitro study. J Appl Oral Sci. 19:483-487. http://dx.doi.org/10.1590/S1678-77572011000500008.

Fernandes, F. S. F., Pereira-Cenci, T., da Silva, W. J., Ricomini Filho, A. P., Straioto, F. G, \& Cury, A.A. D. B. (2011). Efficacy of denture cleansers on Candida spp. biofilm formed on polyamide and polymethyl methacrylate resins. J Prosthet Dent. 105:51-58. https://doi.org/10.1016/S0022-3913(10)60192-8.

Freires, I. A., Bueno-Silva, B., Galvão, L. C. C., Duarte, M. C. T., Sartoratto, A., Figueira, G. M., Alencar, S. M. \& Rosalen, P. L. (2015). The effect of essential oils and bioactive fractions on Streptococcus mutans and Candida albicans biofilms: Confocal analysis. J Evid Based Complementary Altern Med. http://dx.doi.org/10.1155/2015/871316.

Galvão, L. C. C., Furletti, V. F., Bersan, S. M. F., Cunha, M. G., Ruiz, A. L. T. G., Carvalho, J. E., Sartoratto, A., Rehder, V. L. G., Figueira, G. M., Duarte, M. C. T., Ikegaki, M., Alencar, S. M. \& Rosalen, P. L. (2012). Antimicrobial activity of essential oils against streptococcus mutans and their antiproliferative effects. J Evid Based Complementary Altern Med. 40:1-12. http://dx.doi.org/10.1155/2012/751435.

Giordani, C., Santin, R. \& Cleff, M. B. (2015). Levantamento de extratos vegetais com ação anti-Candida no período de 2005-2013. Rev Bras Plantas Med. 17:175-185. http://dx.doi.org/10.1590/1983-084X/12_072.

Glass, R. T., Conrad, R. S., Bullard, J. W., Goodson, L. B., Mehta, N., Lech, S. J. \& Loewy, Z. G. (2010). Evaluation of microbial flora found in previously worn prostheses from the Northeast and Southwest regions of the United States. J Prosthet Dent. 103:384-9. https://doi.org/10.1016/S0022-3913(10)60083-2.

Gonçalves, L. M., Madeira, P. L. M., Diniz, R. S., Nonato, R. F., Siqueira, F. S. F., Sousa, E. M., Farias, D. C. S., Rocha, F. M. G., Rocha, C. H. L., Lago, A. N. D. \& Monteiro, C. A. (2019). Effect of Terminalia catappa Linn. on biofilms of Candida albicans and Candida glabrata and on changes in color and roughness of acrylic resin. Evid Based Complement Alternat Med. 2019:1-8. https://doi.org/10.1155/2019/7481341.

Heidrich, D., Fortes, C. B. B., Mallmann, A. T., Vargas, C. M., Arndt, P. B. \& Scroferneker, M. L. (2018). Rosemary, castor oils, and propolis extract: activity against Candida albicans and alterations on properties of dental acrylic resins. J Prosthodont. 00:1-6. https://doi.org/10.1111/jopr.12746.

Hofling, J. F., Anibal, P. C., Obando-Pereda, G. A., Peixoto, I. A. T., Furletti, V. F., Foglio, M. A. \& Gonçalves, R. B. (2010). Antimicrobial potential of some plant extract again Candida species. Braz J Biol. 70:1065-1068. http://dx.doi.org/10.1590/1807-3107BOR-2014.vol28.0017.

ISO - 10993-5. International Standard Organization (2009) Biological evaluation of medical devices-Part 5: Tests for in vitro cytotoxicity. (3a ed.), International Standard Organization.

Jorge, M. P., Madjarof, C., Ruiz, A. L. T. G., Fernandes, A. T., Rodrigues, R. A. F., Souza, I. M. O., Foglio, M. A. \& Carvalho, J. E. (2008). Evaluation of wound healing properties of Arrabidaea chica verlot extract. J Ethnopharmacol. 118:361-366. https://doi.org/10.1016/j.jep.2008.04.024.

Kuhn, D. M., Chandra, J., Mukherjee, P. K. \& Ghannoum, M. A. (2002). Comparison of biofilms formed by Candida albicans and Candida parapsilosis on bioprosthetic surfaces. Infection and Immunity. 70(2):878-888. https://dx.doi.org/10.1128\%2Fiai.70.2.878-888.2002.

Lee, J. H., El-Fiqi, A., Jo, J. K., Kim, D. A., Kim, S. C., Jun, S. K., Kim, H. W. \& Lee, H. H. (2016). Development of long-term antimicrobial poly(methyl methacrylate) by incorporating mesoporous silica nanocarriers. Dent Mater. 32:1564-1574. https://doi.org/10.1016/j.dental.2016.09.001.

Little, J. W., Falace, D. A. (1987). Dental management of medically compromised patients. Plantas Medicinais no Brasil: nativas e exóticas. (2a ed.), Nova Odessa, Instituto Plantarum.

Lucena-Ferreira, S. C., Ricomini-Filho, A. P., da Silva, W. J., Cury, J. Á. \& Cury, A. A. D. B. (2014). Influence of daily immersion in denture cleanser on multispecies biofilm. Clin Oral Investig. 18:2179-2185. https://doi.org/10.1007/s00784-014-1210-9.

Madeira, P. L. B., Carvalho, L. T., Paschoal, M. A. B., de Sousa, E. M., Moffa, E. B., da Silva, M. A. S., Tavarez, R. J. R. \& Gonçalves, L. M. (2016). In vitro effects of lemongrass extract on Candida albicans biofilms, human cells viability, and denture surface. Front Cell Infect Microbiol. 6:1-9. https://doi.org/10.3389/fcimb.2016.00071.

Mafioleti, L., Silva Junior, I. F., Colodel, E. M., Flach, A. \& Martins, D. T. O. (2013). Evaluation of the toxicity and antimicrobial activity of hydroethanolic extract of Arrabidaea chica (Humb. \& Bonpl.) B. Verl. J Ethnopharmacol.150:576-582. https://doi.org/10.1016/j.jep.2013.09.008.

Medeiros, B. J. L., Costa K. S., Ribeiro, J. F. A., Silva, J. O. C., Barbosa, Júnior W. L. R. \& Carvalho, J. C. T. (2011). Liver protective activity of a hidroethanolic extract of Arrabidaea chica (Humb. and Bonpl.) B. Verl. (pariri). Pharmacognosy Res. 3:79-84. https://doi.org/10.4103/0974-8490.81954.

Ministério da Saúde (2006) Portaria no 971, de 3 de maio de 2006. Política Nacional de Práticas Integrativas e Complementares (PNPIC) no Sistema Único de Saúde. http://bvsms.saude.gov.br/bvs/saudelegis/gm/2006/prt0971_03_05_2006.html. 
Moon, A., Powers, J. M. \& Kiat-Amnuay, S. (2014). Color stability of denture teeth and acrylic base resin subjected daily to various consumer cleansers. $J$ Esth and Rest Dentistry. 26:247-255. https://doi.org/10.1111/jerd.12109.

Moura, J. S., da Silva, W. J., Pereira, T. \& Cury, A. A. D. B., Garcia, R. C. M. R. (2006). Influence of acrylic resin polymerization methods and saliva on the adherence of four Candida species. J Prosthet Dent. 96: 205-11. https://doi.org/10.1016/j.prosdent.2006.07.004.

Nett, J. E. (2014). Future directions for anti-biofilm therapeutics targeting Candida. Expert Rev Anti Infect Ther. 12:375-382. https://doi.org/10.1586/14787210.2014.885838.

Newman, D. J. \& Cragg, G. M. (2012). Natural Products as Sources of New Drugs over the 30 Years from 1981 to 2010. J Nat Prod. 75:311-335. https://doi.org/10.1021/np200906s.

Oliveira, D. P. C., Borrás, M. R. L., Ferreira, C. L. F. \& López-Lozano, J. L. (2009). Atividade anti-inflamatória do extrato aquoso de Arrabidaea chica (Humb \& Bonpl.) B. Verl. sobre o edema induzido por venenos de serpentes amazônicas. Rev Bras Farmacogn. 19:643-649. http://dx.doi.org/10.1590/S0102-695X2009000400024.

Orsi, I. A., Junior, A. G., Villabona, C. A., Fernandes, F. H. \& Ito, I. Y. (2011). Evaluation of the efficacy of chemical disinfectants for disinfection of heatpolymerized acrylic resin. Gerodontology. 28:253-257. https://doi.org/10.1111/j.1741-2358.2010.00400.x.

Padilha, D. M., Hugo, F. N., Hilgert, J. B. \& Dal Moro, R. G. (2007). Hand function and oral hygiene in older institutionalized Brazilians. J Am Geriatr Soc. 55:1333-8. https://doi.org/10.1111/j.1532-5415.2007.01278.x.

Paranhos, H. F., Davi, L. R., Peracini, A., Soares, R. B., Lovato, C. H. \& Souza, R. F. (2009). Comparison of physical and mechanical properties of microwavepolymerized acrylic resin after disinfection in sodium hypochlorite solutions. Braz Dent J. 20:331-335. http://dx.doi.org/10.1590/S010364402009000400012

Paranhos, H. F., Peracini, A., Pisani, M. X., Oliveira, V. C., Souza, R. F. \& Silva-Lovato, C. H. (2013). Color stability, surface roughness and flexural strength of an acrylic resin submitted to simulated overnight immersion in denture cleansers. Braz Dent J. 24:152-156. http://dx.doi.org/10.1590/01036440201302151

Paranhos, H. F., Bezzon, O. L., Davi, L. R., Felipucci, D. N., Silva, C. H. \& Pagnano, V. O. (2014). Effect of cleanser solutions on the color of acrylic resins associated with titanium and nickel-chromium alloys. Braz Oral Res. 28:1-7.

Porta, S. R. S., de Lucena-Ferreira, S. C., da Silva, W. J. \& Cury, A. A. D. B. (2015). Evaluation of sodium hypochlorite as a denture cleanser: a clinical study. Gerodontology. 32:260-266. https://doi.org/10.1111/ger.12104.

Santos, V. C., Garcia, A. L., Richter, M. F., Guecheva, T. N., Henriques, J. A., Ferraz, A. B. \& Picada, J. N. (2013). Evaluation of the mutagenicity and genotoxicity of Arrabidaea chica Verlot (Bignoneaceae), an Amazon plant with medicinal properties. J Toxicol Environ Health A. 76:381-390. https://doi.org/10.1080/15287394.2012.761947.

Solana, C., Ferrer-Luque, C. M., Wang, X., Baca, P., Ruiz-Linares, M. \& Cabrera, T. (2020). Cytotoxic effects of alkaline tetrasodium EDTA irrigating solutions. J Oral Sci. 23;62(3):285-287. https://doi.org/10.2334/josnusd.19-0234.

Tan, C. M., Tsoi, J. K., Seneviratne, C. J. \& Matinlinna, J. P. (2014). Evaluation of the Candida albicans removal and mechanical properties of denture acrylics cleaned by a low-cost powered toothbrush. J Prosthodont Res. 58:243-51. https://doi.org/10.1016/j.jpor.2014.06.002.

Van Den Berg, M. E. (1993). Plantas medicinais na Amazônia, (2a ed.), CNPq/Programa Trópico Úmido.

Vieira, A. P. C., Senna, P. M., Da Silva, W. J. \& Del Bel Cury A. A. (2010). Long-term efficacy os denture cleansers in preventing Candida spp. biofilm recolonization on liner surface. Braz Oral Res. 24: 342-348. https://doi.org/10.1590/s1806-83242010000300014.

Webb, B. C., Thomas, C. J. \& Whittle, T. (2005). A 2-year of Candida-associated denture stomatitis treatment in aged care subjects. Gerodontology. 22:168176. https://doi.org/10.1111/j.1741-2358.2005.00065.x.

Wen, D., Li, C., Di, H., Liao, Y., Liu, H. \& Universal, A. (2005). A universal HPLC method for the determination of phenolic acids in compounds herbal medicines. J Agric Food Chem. 53(17): 6624-9. https://doi.org/10.1021/jf0511291.

Wieckiewicz, M., Opitz, V., Richter, G. \& Boening, K. W. (2014). Physical properties of polyamide-12 versus PMMA denture base material. Biomed Res Int.1-8. http://dx.doi.org/10.1155/2014/150298.

Wiziack, Zago P. M., Oliveira, Sousa I. M., Servat-Medina, L., Jorge, M. P., Lima Neto, L. G., Hass, V., Li X., Tasca Gois Ruiz, A. L., Saxena, D. \& Foglio, M. A. (2020). Standardized Arrabidaea chica Extract Shows Cytoprotective Effects in Zoledronic Acid-Treated Fibroblasts and Osteoblasts. Clin Cosmet Investig Dent. 11;12:327-333. https://doi.org/10.2147/CCIDE.S259158.

Zomorodian, K., Haghighi, N. N., Rajaee, N., Pakshir, K., Tarazooie, B., Vojdani, M., Sedaghat, F., \& Vosoghi, M. (2011). Assessment of Candida species colonization and denture-related stomatitis in complete denture wearers. Med Mycol. 49:208-211.https://doi.org/10.3109/13693786.2010.507605. 